TAO, Vol. 16, No. 5, 989-1015, December 2005

\title{
A Sensitivity Study of Regional Climate Simulation to Convective Parameterization Schemes for 1998 East Asian Summer Monsoon
}

\author{
Dong-Kyou Lee ${ }^{1, *}$, Dong-Hyun Cha ${ }^{1}$, and Suk-Jin Choi ${ }^{1}$
}

(Manuscript received 26 April 2004, in final form 8 July 2005)

\begin{abstract}
A sensitivity study of regional climate simulations over East Asia to three convective parameterization schemes (CPSs), the Grell, Kain-Fritsch, and Anthes-Kuo schemes, was conducted using a regional climate model, SNURCM with a $60 \mathrm{~km}$ horizontal resolution. Nesting experiments with a $20 \mathrm{~km}$ horizontal resolution were also performed in order to investigate the sensitivity of CPSs to horizontal resolution.

In all runs with $60 \mathrm{~km}$ horizontal resolution, seasonal mean precipitation, low- and upper-level wind, and temporal and spatial variation of monsoon fronts over East Asia were simulated with a certain difference between CPSs. With higher horizontal resolution, all the schemes were likely to increase slightly the total precipitation amount and the precipitation intensity due to the increase of convective rain, but differences in the spatial distribution of precipitation between CPSs were relatively small. There were prominent differences in vertical profiles of wind, temperature, water vapor, and atmospheric hydrometeors amongst CPSs, although the vertical structures of those in GR and KF runs were similar to each other. Sensitivities of the vertical structure of most atmospheric variables to horizontal resolution were relatively smaller than they were to CPSs except for cloud water. Surface energy fluxes, in particular incoming solar radiation and latent heat between CPSs were different to each other because of differences in the vertical structure of atmospheric hydrometeors. Diurnal variation of precipitation was also sensitive to not only CPSs but also horizontal resolution.

In this study, the AK scheme reproduced the East Asian Summer precipitation properly because of intrinsic triggering assumptions and the spectral nudging technique. The GR scheme was on the whole suitable to simulate the general features of East Asian summer monsoon in 1998 such
\end{abstract}

\footnotetext{
${ }^{1}$ Atmospheric Sciences Program, School of Earth and Environmental Sciences, Seoul National University, Seoul, Korea.

* Corresponding author address: Prof. Dong-Kyou Lee, Atmospheric Sciences Program, School of Earth and Environmental Sciences, Seoul National University, Seoul, Korea; E-mail: dklee@snu.ac.kr
} 
as heavy precipitation, atmospheric vertical structure, and temporal evolution of the East Asian Summer monsoon. The KF scheme had the worst statistics in precipitation simulation due to large convective precipitation portion. Consequently, the AK and GR schemes simulated more reasonably the 1998 summer flood over East Asia which was affected by anomalous large-scale conditions.

\section{(Key words: Regional climate model, Convective parameterization schemes, Sensitivity study, East Asian summer monsoon)}

\section{INTRODUCTION}

Since the successful inception of regional climate by Dickinson et al. (1989) and Giorgi (1990), much effort has been devoted to the development, evaluation, and application of regional climate models (RCMs). In spite of enormous efforts to develop and improve RCMs, there still remain several debatable issues in RCM studies such as spin-up of precipitation, uncertainty of large-scale forcing data, parameterization of physical process, choice of model domain and its spatial resolution, and lateral boundary condition technique (Leung et al. 2003). RCMs become sensitive to internal/external forcings which are represented by the physical parameterizations of models. One physical process which has a pronounced influence on simulated results is cumulus convection. Since the typical range of horizontal resolution in regional climate modeling remains about 10 60 km, most RCMs have used not only an explicit moisture scheme but also a convective cumulus parameterization scheme (CPS). Using different convective parameterization schemes (CPSs) can induce dissimilar results in regional climate simulation, since each CPS includes assumptions and parameters based on an individual formalism. Therefore, the adequate selection of CPSs can be particularly important in regional climate modeling.

The sensitivity of model simulations to various cumulus parameterization schemes is an attractive topic in numerical weather prediction (NWP) and climate modeling studies. There is no universal conceptual framework for cumulus parameterization at present, so the general applicability of any particular scheme is not obviously possible. In a series of tests of gridscale resolvable precipitation and cumulus convection schemes using the NCAR RegCM2, Giorgi and Shields (1999) showed that the Grell scheme with a simplified explicit cloud microphysics scheme had better performance in simulating precipitation than either a Kuo-type scheme or a newly implemented mass-flux scheme (Zhang and McFarlane 1995) over the United States. Recently, comparative studies of available cumulus parameterization schemes in the MM5 (the fifth-generation Pennsylvania State University / National Center for Atmospheric Research Mesoscale Model, Grell et al. 1994) such as Anthes-Kuo, Grell, Kain-Frtitsch, and Betts-Miller schemes were conducted not only for short-range weather prediction (Wang and Seaman 1997) but also for 2.5-month long regional climate simulation (Gochis et al. 2002) over the United States. Differences of the simulated precipitation resulting from various cumulus parameterization schemes were more significant in their long-term simulation than in 
their short-term forecast. Although both studies confirmed that none of these schemes was able to produce perfect simulation of observations in the model domain, the Kain-Fritsch scheme produced better results in terms of statistical estimates of surface and upper-air variables as well as precipitation. However, this does not mean that this scheme is superior to others irrespective of cases, regions, seasons, and combinations with other physical processes in the model. For example, the regional climate simulations of summertime precipitation in East Asia using about $50 \mathrm{~km}$ horizontal grid spacing indicated that in general a Kuo-type cumulus scheme could produce good results (Liu et al. 1996; Lee and Suh 2000), despite much unrealistic convective precipitation greater than $70 \%$ of the total precipitation in the Kuo-type scheme.

A number of studies of regional climate over East Asia using RCMs have been done, but nearly no attempt to measure the sensitivity of regional climate simulation to CPSs has been made. Sensitivity of regional climate simulation over East Asia to model horizontal resolution has been investigated in a few studies (e.g., Lee et al. 2004), but the sensitivity of East Asian summer monsoon precipitation simulation to CPSs and model horizontal resolutions have not been found. The objectives of this paper are to compare the results between different CPSs in the regional climate simulations, in particular focusing on reproduction of the heavy precipitation occurring over East Asia during the 1998 summer, and to investigate the sensitivity of summer monsoon precipitation to cumulus parameterization and horizontal resolution in the simulations. Regional climate simulations of the severe flood over East Asia during the summer of 1998 were conducted by Wang et al. (2003), Lee et al. (2004), and so on.

The regional climate model and the cumulus convection parameterization schemes used in this study are described in section 2 . We analyze simulated seasonal mean features in section 3. The energy budgets and vertical structures are presented in section 4 , and the diurnal variation in section 5. Finally, the summary and conclusions are given in section 6 .

\section{MODEL DESCRIPTION AND EXPERIMENTS}

\subsection{The Regional Climate Model}

The regional climate model used in this study is Seoul National University Regional Climate Model (SNURCM). SNURCM consists of a mesoscale model, MM5 (Grell et al. 1994) for the atmosphere, and an advanced and comprehensive land surface parameterization scheme, the NCAR land surface model (NCAR LSM) (Bonan 1996) for the land surface and soil layers. To reduce systematic bias, a spectral nudging technique (von Storch et al. 2000) is also implemented for lateral boundary handling with a modified relaxation method (Liang et al. 2001).

The NCAR LSM is a mosaic-type, one-dimensional model for energy, momentum, and water exchange between the atmosphere and the land (Bonan 1996). It contains one vegetation layer, one snow layer and six soil layers. It considers not only the surface energy budgets for ground, vegetation, and soil layers but also the soil hydrology in detail. That is, it parameterizes interception, through-fall, snow accumulation and melt, infiltration, surface and sub-surface runoff, and redistribution of water with the soil column to simulate canopy, snow and soil water in the soil layer. Vegetation effects are included by allowing for twelve plant types that differ in leaf and stem areas, root profile, height, leaf dimension, optical properties, stomatal 
physiology, roughness length, displacement height, and biomass. These 12 plant types are combined to form 28 different vegetated surfaces (Olson et al. 1983) so that each comprises of multiple plant types and bare ground. Soil effects are considered by allowing thermal (heat capacity and thermal conductivity) and hydraulic properties (porosity, saturated hydraulic conductivity, saturated metric potential, and slope of retention curve) to vary as functions of sand and clay fractions. Soils also differ in color, which affects soil albedo. Consequently, each grid cell in the NCAR LSM is assigned a surface type, a fraction representing the coverage by different soil textures (percent sand, silt, and clay), lakes and wetlands, which is an advantage that has the potential to be applied for regional climate modeling with very high resolution. A more detailed description and data sources for soil properties can be found in Bonan (1996).

Forcing in the spectral nudging technique is stipulated not only at the lateral boundaries, but also in the model interior. This is maintained by adding nudging terms to the model equations of horizontal winds in the spectral domain with maximum efficiency for large scales and no effect for small scales. There have been previous studies that share similarities in terms of scale separation using a spectral method (Kida et al. 1991), but the spectral nudging technique used in this study is slightly different from the spectral method. The small-scale regime of model solution is not changed in both methods. However, the large-scale regime of the model solution is replaced with that of the driving forcing data (i.e., GCM and reanalysis) in the spectral method, while that of the model solution is combined with that of the driving forcing data using weighting coefficients in the spectral nudging method. A detailed description of the spectral nudging technique can be found in von Storch et al. (2000).

\subsection{Experimental Setup}

In this study, six experiments were run using SNURCM. Basically, three sets of experiments in a $60 \mathrm{~km}$ resolution domain were performed for three different CPSs; the Grell scheme (hereafter referred to as the GR scheme) (Grell 1993), the Kain-Fritsch scheme (hereafter referred to as the KF scheme) (Kain and Fritsch 1990) and the Anthes-Kuo scheme (here after referred to as the AK scheme) (Anthes 1977). Also, another three sets of experiments in a $20 \mathrm{~km}$ resolution domain nested in the $60 \mathrm{~km}$ resolution domain were performed in a similar way. The three experiments with $60 \mathrm{~km}$ horizontal resolution are aimed at simulating regional climate features over the Asian continent during the summer (May, June, July, and August) of 1998. The other three experiments in the nested domain are to investigate the sensitivity of simulated heavy precipitation to the three CPSs for the flood events occurring over central China.

In the experiments with $60 \mathrm{~km}$ horizontal resolution (GR60, KF60, and AK60), the model domain consisted of 151 by 111 grid points in the zonal and meridional direction $(9000 \mathrm{~km} \times$ $6000 \mathrm{~km}$ ), respectively, centered at $35^{\circ} \mathrm{N}$ and $105^{\circ} \mathrm{E}$. In the nested experiments (GR20, KF20, and AK20), the model domain had 100 by 100 grid points with $20 \mathrm{~km}$ grid distance in the horizontal, focusing on the severe flood region over southern and central China, and Taiwan (Fig. 1). In the vertical, all experiments used 23 layers between the $70 \mathrm{hPa}$ model-top and the surface. All physics parameterizations were identical in all experiments except for the CPSs; 


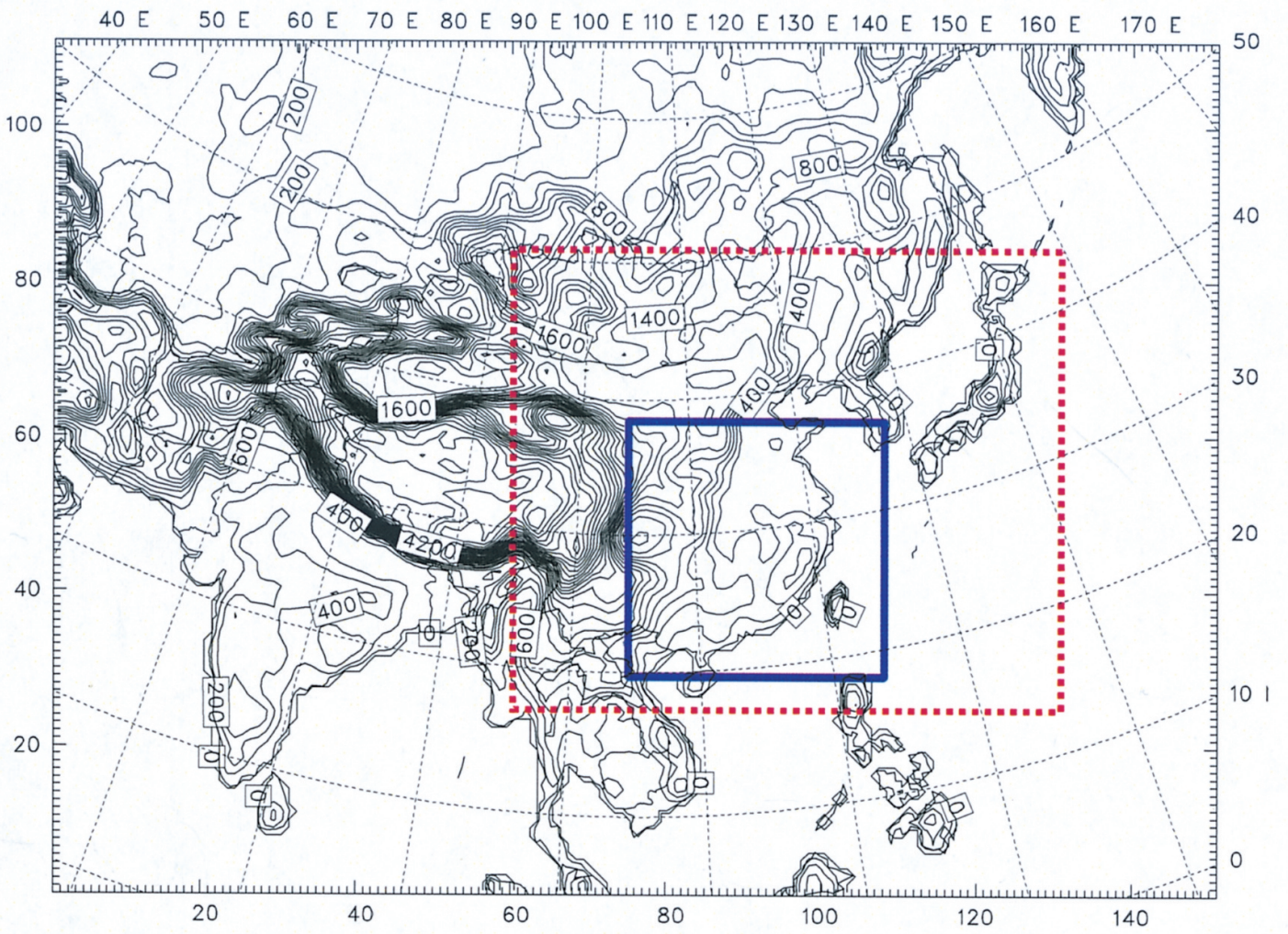

Fig. 1. Model domains and topography (m). The inner rectangle (dashed) and square (solid) indicate the analysis areas in the $60 \mathrm{~km}$ domain and the nested domain with $20 \mathrm{~km}$ horizontal resolution, respectively. The contour intervals are $200 \mathrm{~m}$.

the simple ice cloud microphysics (Dudhia 1989), the non-local planetary boundary layer physics (Hong and Pan 1996), and the CCM2 radiative transfer package (Briegleb 1992). Since this study focuses on simulated precipitation, the grid-scale resolvable and cumulus convection parameterization schemes are described.

In the simple ice explicit moisture scheme (Dudhia 1989), it is assumed that there is no super-cooled water nor super-warmed snow and/or ice of any kind. This scheme optionally allows for an ice-phase below $0^{\circ} \mathrm{C}$, where cloud water is treated as cloud ice and rain is treated as snow. In this scheme, melting is assumed to take place within one model-level of the freezing point, so that cloud ice and snow melt immediately on descending below the $0^{\circ} \mathrm{C}$ level, and cloud water and rain freeze immediately upon ascending above this level. This assumption is good for slowly falling particles, but does not capture the true history of heavy particles 
subjected to intense vertical motion.

The Grell scheme is activated using a trigger mechanism similar to that used in the KainFritch scheme in that it is not activated until a lifting-depth criterion is met that indicates there is sufficient lift to access potential buoyant energy. In this scheme, it is assumed that there is no direct mixing laterally with the environment (no entrainment or detrainment), except at the level of the origin or termination of updrafts and downdrafts. Therefore, mass flux is constant with height. Because of the absence of lateral mixing, it is not necessary to assume that the fractional area coverage of updrafts and downdrafts in the grid column is small. The subgrid precipitation is calculated as

$$
P R=I_{l} m_{b}(1-\beta),
$$

where $I_{l}$ is the integrated condensate in the updraft, $m_{b}$ is the cloud-base mass flux of the updraft, and $(1-\beta)$ is the precipitation efficiency, which is assumed to be a function of the mean wind shear in the lower troposphere. The effects of the convective-scale downdrafts are parameterized in this scheme.

The Kain-Fritsch convection parameterization scheme is a combination of the one-dimensional entraining /detraining plume model of Kain and Fritsch (1990) and the convection parameterization framework of Fritsch and Chappell (1980). The closure assumption in this scheme is the critical CAPE-removal closure assumption that the convection is determined by the CAPE at a grid point, and once convection is triggered, the CAPE is assumed to be removed in a grid column within an advective time period. This scheme utilizes an improved cloud model which is reformulated into an entraining-detraining model, with parcel buoyancy calculated as a function of parcels mixed laterally between the environment and the updrafts. The convective precipitation is computed as

$$
P R=E S,
$$

where $E$ is the precipitation efficiency, which is assumed to be a function of the mean wind shear in the lower troposphere and cloud base height, and $S$ is the sum of the vertical fluxes of vapor and liquid at about $150 \mathrm{hPa}$ above the lifting condensation level.

The Anthes-Kuo scheme is a variation of the original Kuo scheme (Kuo 1974). Closure is based on the assumption that the intensity of subgrid deep convection is proportional to the vertically integrated convergence of water-mass in a grid column. The scheme uses the column-integrated moisture convergence $M_{t}$ to determine where convection will occur and how intense it will be. Convection is initiated when conditional instability exists (determined by parcel theory) and $M_{t}$ exceeds a threshold value in the column. The moisture convergence is partitioned into moistening of the column and convective precipitation, such that the precipitation defined as

$$
P R=(1-b) M_{t},
$$


where $b=2(1-\overline{R H})$ and $\overline{R H}$ is the mean relative humidity of the column. This scheme does not include a cloud model nor parameterized convective downdrafts.

For lateral boundary forcing, 15 and 10 grid points were used for the buffer zone in experiments with $60 \mathrm{~km}$ and $20 \mathrm{~km}$ horizontal resolution, respectively. In the spectral nudging technique applied to the horizontal wind fields in both experiments, the large-scale spectral regimes were assumed to have wave numbers up to seven and five in zonal and meridional directions, respectively, in GR60, KF60 and AK60, and wave numbers up to two in both directions were assumed for the large-scale spectral regimes in GR20, KF20 and AK20. These wave numbers of all experiments corresponded to approximately $1000-1200 \mathrm{~km}$ in wavelength.

In order to provide initial and boundary data to drive the regional climate model, upper-air variables (zonal and meridional winds, temperature, and relative humidity) of a $2.5^{\circ} \times 2.5^{\circ}$ interval at 13 pressure levels from 1000 to $70 \mathrm{hPa}$ and surface variables of T63 Gaussian grids (approximately $1.875^{\circ} \times 1.904^{\circ}$ interval) are obtained from 6-hourly NCEP/NCAR reanalysis 2 (Kistler et al. 2001) and interpolated to the model grids bi-linearly. The observed sea surface temperature (SST) is updated every 24 hours from the $1^{\circ} \times 1^{\circ}$ weekly data (Smith and Reynolds 1998). The surface boundary conditions required for the NCAR LSM are surface types, soil color, soil texture and lake/wetlands fraction. The sources of these data were described in Bonan (1996). The SNURCM also requires initial soil moisture and temperature fields which were obtained from an off-line simulation of the NCAR/LSM after it reached an equilibrium state under the forcing of 6-hourly atmospheric values and surface radiation from NCEP reanalysis as well as daily observed precipitation from the NCEP/Climate Prediction Center (CPC) archives for the year of 1998. The model was integrated for four months (MJJA) starting from 1 May 1998.

The simulation results were compared with the driving fields and the observation data in order to evaluate model precipitation based on different CPS schemes. The station-observed precipitation and 2-m height daily maximum/minimum temperatures obtained from NCEP/ CPC were used after being converted to the model grid system using the Multi-quadric Interpolation method (MQD) (Nuss and Titley 1994). The CPC Merged Analysis of Precipitation (CMAP) data (Xie and Arkin 1997) were also used to evaluate the monthly precipitation over the ocean, although there was the bias of CMAP over the ocean due to the use of atoll data as demonstrated by Yin et al. (2004).

\section{SEASONAL MEAN SYNOPTIC FIELDS}

\subsection{Results of $60 \mathrm{~km}$ Horizontal Resolution}

The record-breaking abnormal floods over East Asia occurred during the summer of 1998. Ding and Liu (2001) demonstrated that this severe flood over East Asia during the 1998 summer was related to the prolonged impact of the strongest El-Niño (1997/98) activity of the last century. More than $150 \%$ of the normal rainfall which was observed over most of East Asia resulted in a number of casualties and tremendous damage in East Asian countries.

Figure 2 shows seasonal mean precipitation over East Asia during the summer (JJA) of 1998 in observation and simulations. In the summer of 1998, extreme floods over southern 

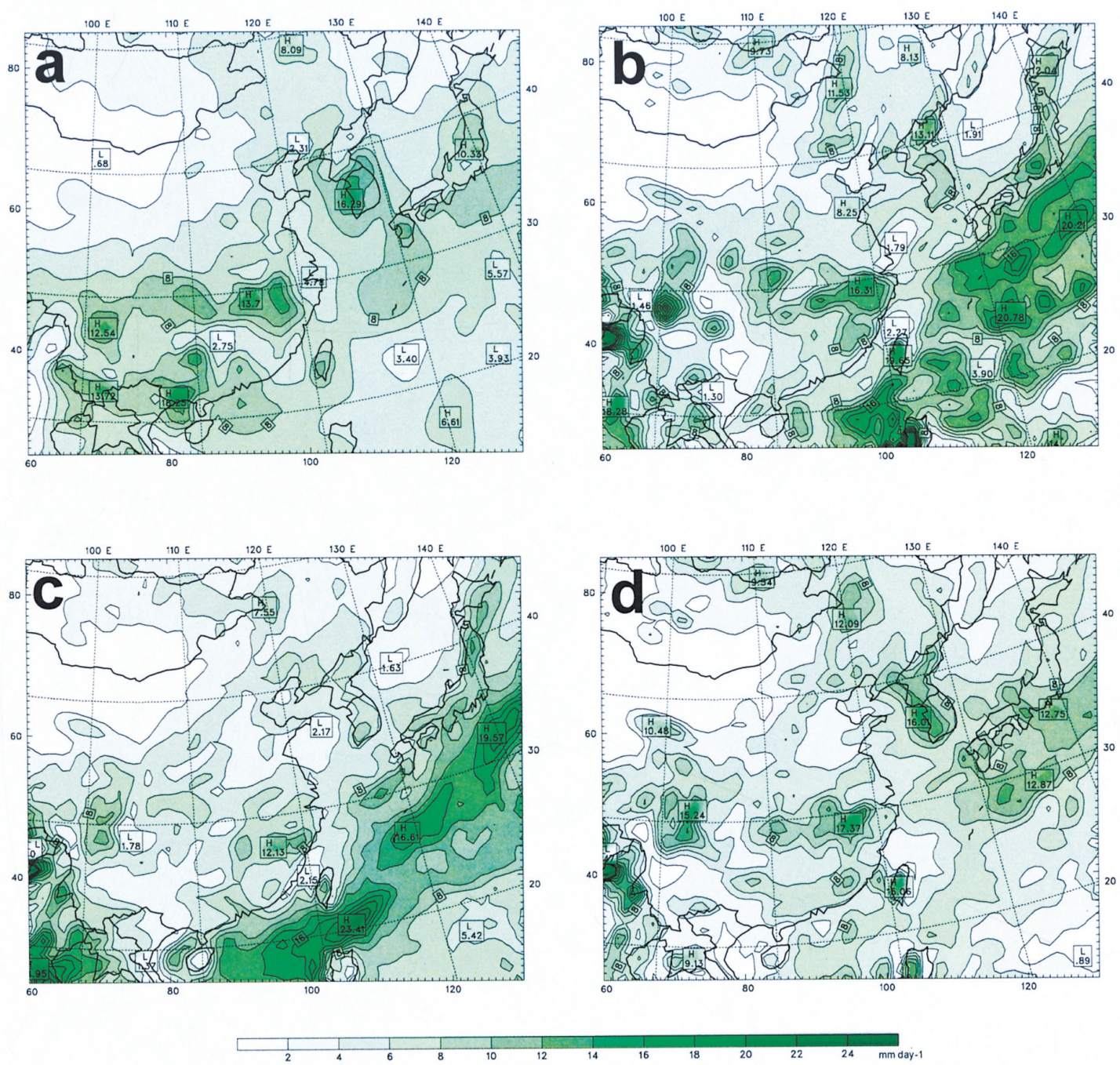

Fig. 2. Seasonal mean precipitation over East Asia during the summer of 1998 (JJA) in (a) observation, (b) GR60, (c) KF60, and (d) AK60. The contour intervals are $2 \mathrm{~mm} \mathrm{day}^{-1}$.

China $\left(105-116^{\circ} \mathrm{E}, 22-25^{\circ} \mathrm{N}\right)$ and the Yangtze River Basin (YRB) region $\left(105-120^{\circ} \mathrm{E}\right.$, $28-30^{\circ} \mathrm{N}$ ) occurred during June and July, and consecutive heavy rainfall events over the Korean Peninsula occurred during late July to mid August. The extreme flood over the YRB region was reproduced reasonably in all $60 \mathrm{~km}$ runs, but in KF60, the amount of precipitation was relatively small compared with observation and other $60 \mathrm{~km}$ runs. The flood over southern China was not simulated properly in any $60 \mathrm{~km}$ runs, and the heavy rainfall over Korea was not captured reasonably except for in the AK60 run. In AK60, the precipitation over the 
Northwestern Pacific was in good agreement with observation, but that was overestimated in GR60 and KF60. A very small amount of precipitation over the Mongolian region and northern China was well reproduced in all $60 \mathrm{~km}$ runs.

To further evaluate the model performance in simulation of precipitation between GR60, KF60 and AK60, the seasonal mean precipitation averaged over the land and ocean in the analysis region was calculated. Table 1 shows the statistics of the observed and simulated seasonal mean precipitation, and their bias, spatial correlation coefficient and root mean square error. Over the land, the GR scheme overestimated precipitation slightly, but the KF and AK schemes underestimated it to some extent. Over the ocean, the GR and KF schemes overestimated precipitation by $30 \%$ of observation, and the AK scheme underestimated it slightly. In GR60 and KF60, more non-convective precipitation was simulated than convective precipitation, while most precipitation was convective precipitation in AK60. In the GR and KF schemes, the spatial correlation coefficient was much larger over the land than over the ocean, whereas it was nearly the same over the land and the ocean in the AK scheme. The root mean square error over land was not large amongst any of the schemes but over the ocean, the error of GR60 and KF60 was almost double compared to AK60 as shown in Fig. 1. In the statistics of seasonal mean precipitation, there were pronounced differences of simulated precipitation amongst $60 \mathrm{~km}$ runs, and the statistics of precipitation in the AK60 run was the most reasonable over both the land and ocean compared with the GR60 and KF60 run.

One of the reasons that the simulated precipitation is different between the $60 \mathrm{~km}$ runs is convective precipitation in the CPSs, because each CPS has intrinsic assumptions and parameters. Although the GR scheme and KF scheme are a mass-flux type scheme, their assumptions and parameters are to some extent different from each other as mentioned in section 2.2. Convective precipitation is determined by the parameter of precipitation efficiency and

Table 1. Statistics of observed and simulated seasonal mean precipitation $\left(\mathrm{mm} \mathrm{day}^{-1}\right)$ in the summer of $1998(\mathrm{JJA})$ averaged over the analysis region. Bias, S.C. and RMSE indicate the seasonal mean bias, spatial correlation coefficient, and root mean square error between simulation and observation, respectively. See Fig. 1 for the analysis region.

\begin{tabular}{|c|c|c|c|c|c|c|c|c|}
\hline \multirow{2}{*}{ Areas } & \multirow{2}{*}{ Experiments } & \multirow{2}{*}{ Obs } & \multicolumn{3}{|c|}{ Simulation } & \multirow{2}{*}{ Bias } & \multirow{2}{*}{ S.C. } & \multirow{2}{*}{ RMSE } \\
\hline & & & Total & Convective & $\begin{array}{c}\text { Non- } \\
\text { convective }\end{array}$ & & & \\
\hline \multirow{3}{*}{ Land } & GR60 & \multirow{3}{*}{5.1} & 5.4 & 1.4 & 4.0 & 0.3 & 0.46 & 3.9 \\
\hline & KF 60 & & 4.7 & 1.8 & 2.9 & -0.4 & 0.46 & 3.3 \\
\hline & AK60 & & 5.0 & 4.2 & 0.8 & -0.1 & 0.49 & 3.3 \\
\hline \multirow{3}{*}{ Ocean } & GR60 & \multirow{3}{*}{6.3} & 8.4 & 2.6 & 5.8 & 1.9 & 0.36 & 4.5 \\
\hline & KF60 & & 8.4 & 5.5 & 3.0 & 1.9 & 0.32 & 4.6 \\
\hline & AK 60 & & 5.8 & 4.9 & 0.9 & -0.5 & 0.49 & 2.4 \\
\hline
\end{tabular}


vertical mass flux in both schemes. The precipitation efficiency in the GR scheme is assumed to be a function of mean-wind shear in the lower troposphere, while that in the KF scheme is assumed to be a function of mean-wind shear and cloud-base height. The mean-wind shear also can be different between the GR and KF runs. In the experiment of this study, wind shear in the GR run was larger than that in the KF run, so the precipitation efficiency in the GR run was smaller than that in the KF run. Therefore, the ratio of the low convective precipitation to the total precipitation in the GR run resulted from the small parameter of precipitation efficiency. Wang and Seaman (1997) had similar result to that in this study. In addition, there is prominent difference in entrainment/detrainment processes between the KF and GR scheme as also explained in section 2.2. This difference can also result in dissimilar vertical mass flux between the two schemes. Therefore, the differences in the parameter of precipitation efficiency and the entrainment/detrainment processes between the GR and KF scheme resulted in the different simulated convective precipitation. In the meanwhile, the convective precipitation in the AK scheme is different from that in the GR and KF scheme, since convective precipitation is determined by grid-scale moisture convergence and relative humidity.

In this study, this difference in convective precipitation amongst the three CPSs caused the different simulated non-convective precipitation. The extreme flood over East Asia during the summer of 1998 resulted from anomalous large-scale synoptic conditions such as the intensified upper- and low-level wind, and increased low-level moisture compared with a normal year (Ding and Liu 2001; Lee et al 2004). Therefore, the heavy precipitation over East Asia during the summer of 1998 was dominated by large-scale precipitation (i.e., non-convective precipitation), which was related to the quasi-stationary monsoon front. KF60 simulated less non-convective precipitation, because it simulated an enhanced convective process compared to GR60. If the CPS simulates more convective precipitation, the amount of remaining water vapor, which can be condensed by an explicit moisture scheme (EMS), decreases and also the air temperature increases due to latent heat release by the CPS, so that non-convective precipitation can be less resolved by an EMS. Therefore, KF60 simulated less total precipitation because of its underestimation of non-convective precipitation. In GR60, most of precipitation was simulated as non-convective precipitation due to less convective precipitation, so that GR60 simulated the largest precipitation among the three schemes. The reason that more reasonable precipitation was simulated in AK60 can be understood in terms of the triggering assumption of convection. Summer precipitation over East Asia is significantly affected by large-scale synoptic fields. For example, Xue et al. (2004) and Kang et al. (2004) showed that anomalous precipitation over East Asia was related to large-scale moisture convergence rather than local surface evaporation. In the AK scheme, convective precipitation is determined by vertically integrated moisture convergence and atmospheric relative humidity, which are characterized by large-scale synoptic fields. Therefore, AK60 simulated reasonably summer precipitations over East Asia which was characterized by the monsoon circulation, although it produced a relatively large portion of convective precipitation to total precipitation.

Another reason that different precipitation resulted among $60 \mathrm{~km}$ runs is related to the difference in monsoon circulations. In $60 \mathrm{~km}$ runs, the reasonable simulation of the monsoon circulation is important, because the heavy precipitation over East Asia during the summer of 1998 resulted from the abnormal synoptic-scale conditions. Figure 3 shows the seasonal mean 

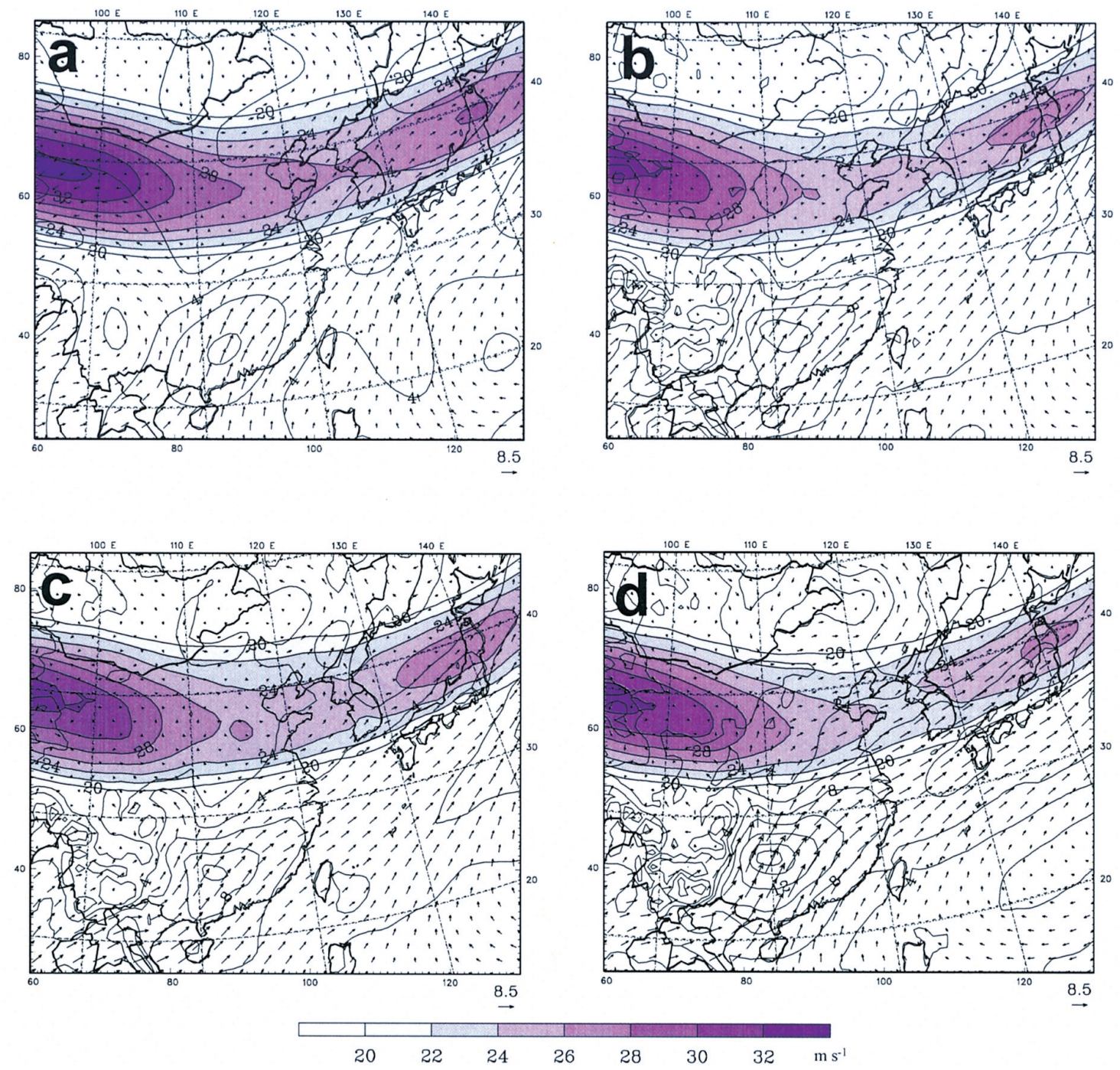

Fig. 3. Seasonal mean $850 \mathrm{hPa}$ wind vector and speed with $200 \mathrm{hPa}$ wind speed (shaded) superposed over East Asia during the summer of 1998 (JJA) in (a) NCEP reanalysis, (b) GR60, (c) KF60, and (d) AK60. The contour intervals are $2 \mathrm{~m} \mathrm{sec}^{-1}$.

(JJA) $850 \mathrm{hPa}$ and $200 \mathrm{hPa}$ wind fields in the NCEP/NCAR reanalysis and simulations. In the reanalysis, the $200 \mathrm{hPa}$ westerly jet extended from northwestern China to Korea and Japan with a minimum speed near Korea, and the $850 \mathrm{hPa}$ southwesterly wind which was related to the subtropical northwestern Pacific high extended from the South China Sea to central China, Korea and Japan. In all $60 \mathrm{~km}$ runs, the upper-level jet was underestimated, and the low-level 
flows were overestimated, in particular, by a factor of around two in the low-level wind speed over southern China in AK60 compared to the reanalysis. However, the spatial distributions of the monsoon circulation in all runs corresponded to the reanalysis due to the implementation of the spectral nudging technique. Therefore, the spatial patterns of precipitation were simulated properly in all $60 \mathrm{~km}$ runs. It is noteworthy that the difference in low-level wind amongst CPSs was very prominent compared to that in upper-level wind.

Since large differences in low-level wind can be associated with the sensitivity of surface air temperature to the CPS, seasonal mean (JJA) surface air temperature for simulations and observation was analyzed in Fig. 4. The observed surface air temperature obtained from NCEP/ CPC was used after being converted from the stations to the model grids. A correction for topography difference between station measure and model was made by assuming a standard atmospheric lapse rate $\left(6.5^{\circ} \mathrm{C} \mathrm{km}^{-1}\right)$ before interpolation. The spatial distributions of surface air temperature in all runs were close to those in observation, although all runs tended to underestimate surface air temperature in comparison with observation. The cold bias over central China and southern China was smallest in the AK run, while it was largest in the KF run. The temperature gradient in the AK run between the land and the ocean was relatively large compared with other runs, so that the strength of low-level wind in the AK run was more enhanced in the simulations compared with other runs. One of the possible reasons for the difference in surface air temperature amongst $60 \mathrm{~km}$ runs is that incoming solar radiation at the surface is sensitive to the CPS. This sensitivity will be explained in detail in section 4 . Also, the reason for the outstanding cold bias in the KF and GR runs can be associated with the downdraft in the convection process, which has a cooling effect, implemented only in these schemes.

In order to compare the East Asia monsoon development and activity amongst different CPSs, we analyzed the time-latitude cross section of daily precipitation (Fig. 5) and the 850 $\mathrm{hPa}$ equivalent temperature ${ }^{1}$ (Fig. 6) averaged between $110^{\circ}$ and $120^{\circ} \mathrm{E}$ from 1 May to 31 August in 1998. In observations, the onset of monsoon precipitation appeared over southern China $\left(20-25^{\circ} \mathrm{N}\right)$ in the middle of May. Heavy precipitation occurred over southern China in early June, advanced northward to central China in mid June and expanded to northern China and southern China until the end of June. Then, heavy rainfall over southern China occurred again in early July and expanded to central and northern China until mid August. Therefore, the record-breaking flood over East China in the summer of 1998 was attributable to these abnormal monsoon activities.

In all the $60 \mathrm{~km}$ runs, the precipitation over the south region of China in late May was underestimated in comparison with observation. In particular, the KF scheme almost missed capturing the onset of monsoon precipitation. All schemes simulated the transition of monsoon precipitation such as its occurrence over southern China in early June and the advance to central and northern China until the end of June. All schemes tended to underestimate heavy precipitation over southern China in early June, but the AK scheme simulated it closer to

\footnotetext{
${ }^{1}$ Here, the equivalent temperature is defined as $T_{e}=T+L_{\nu} q / C_{p}$, where $T$ is the air temperature, $L_{\nu}$ the latent heat, $q$ the mixing ratio of water vapor, $C_{p}$ the specific heat at constant pressure.
} 

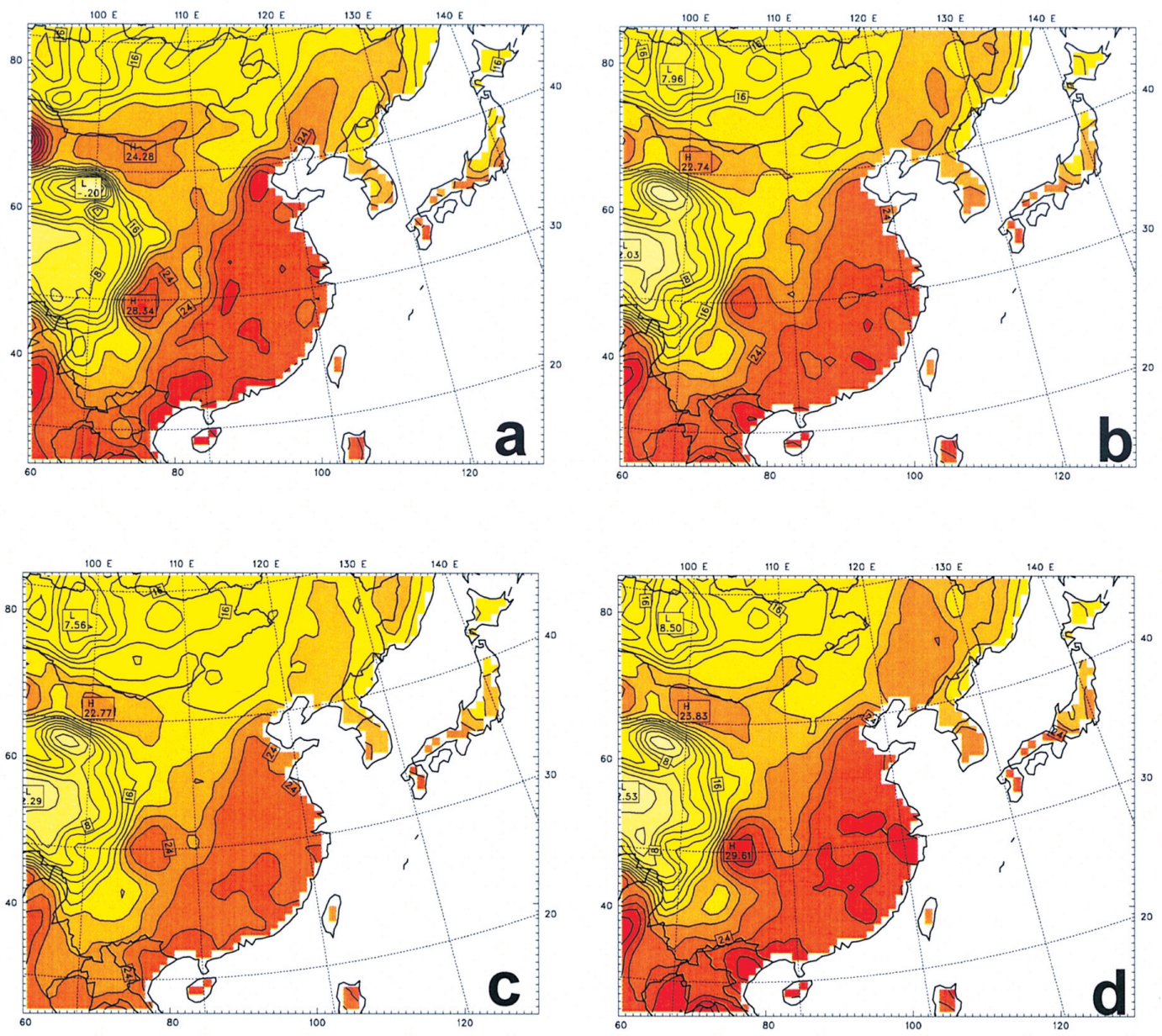

Fig. 4. Seasonal mean surface air temperature over East Asia during the summer of 1998 (JJA) in (a) observation, (b) GR60, (c) KF60, and (d) AK60. The contour intervals are $2^{\circ} \mathrm{C}$.

observation than the other schemes. The flood over the YRB region in mid-June and the movement of the flood region from central China to northern China until the end of June were captured reasonably by all schemes, but only the GR scheme simulated monsoon precipitation with weak precipitation intensity which expanded from central China to southern China during late June. In all runs, the second occurrence of monsoon precipitation over southern China in early July was captured, and the GR scheme simulated precipitation over central and northern China in late July more reasonably than the other schemes. 
(a) observation

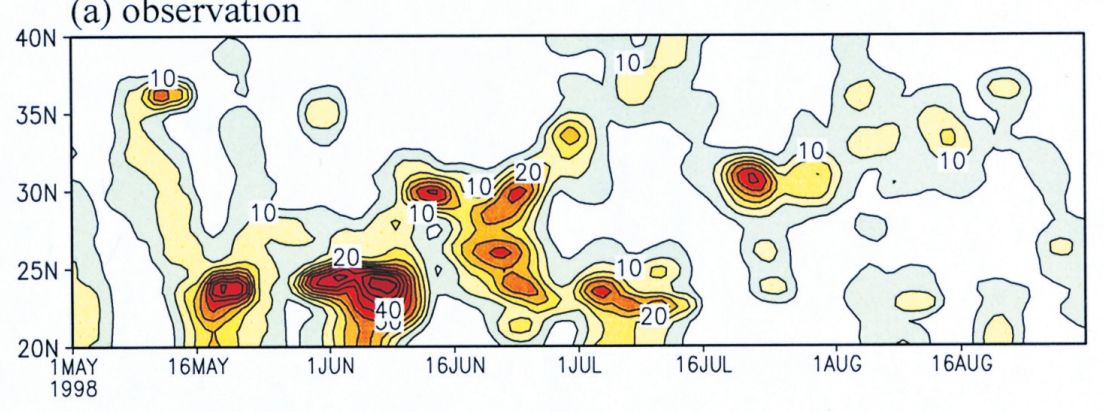

(b) GR60

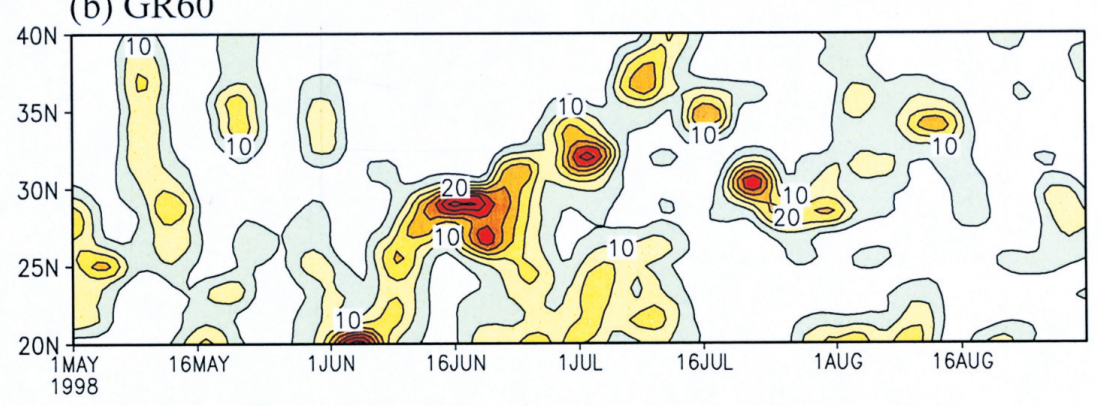

(c) KF60
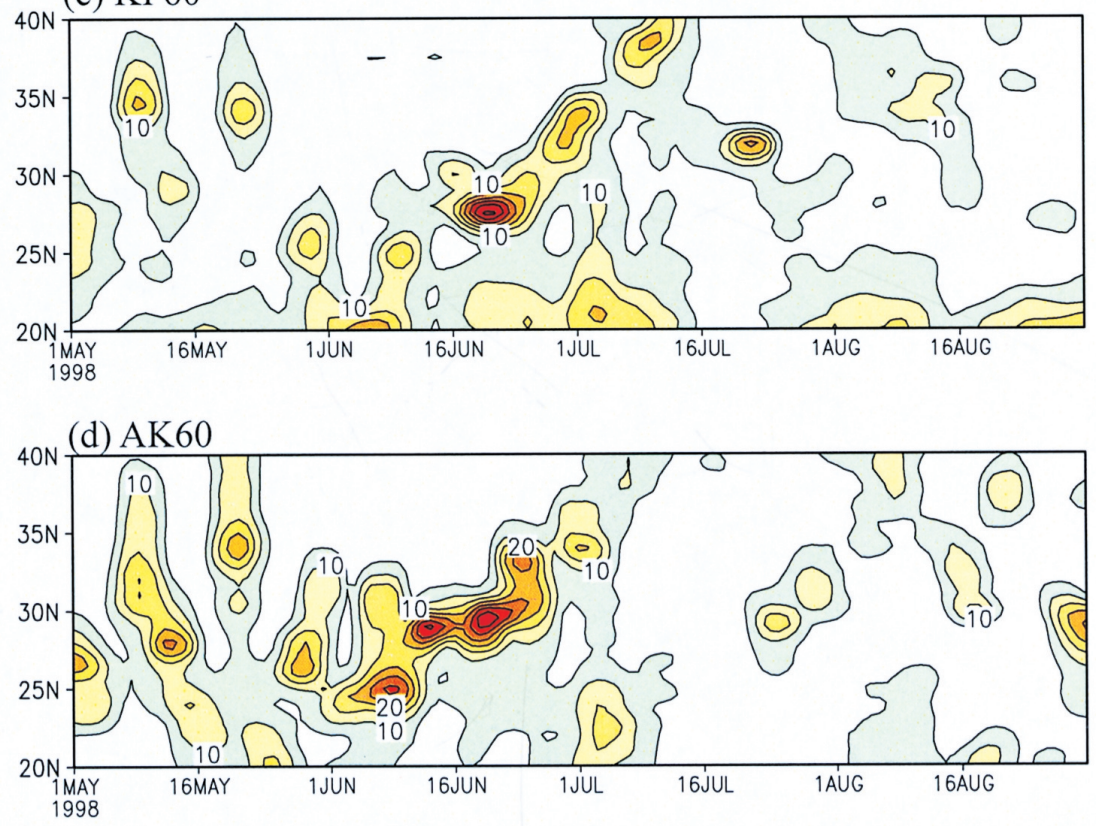

Fig. 5. Time-latitude distribution of daily precipitation (mmday-1) averaged between $110^{\circ}$ and $120^{\circ} \mathrm{E}$ from 1 May to 31 Aug. in 1998 in (a) observation, (b) GR60, (c) KF60, and (d) AK60. The contour intervals are $5 \mathrm{~mm} \mathrm{day}^{-1}$. 
(a) observation

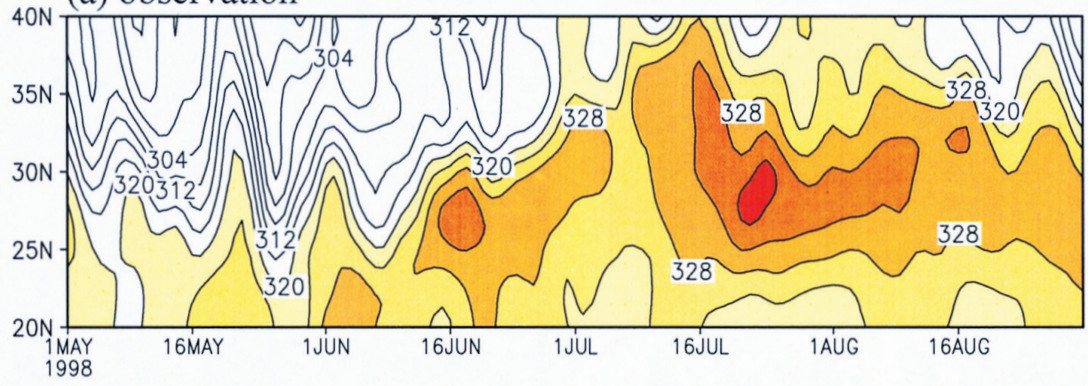

(b) GR60

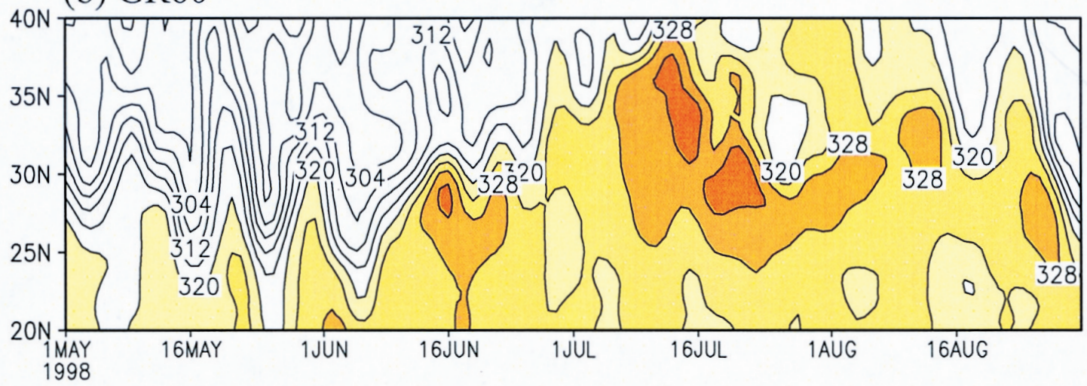

(c) KF60
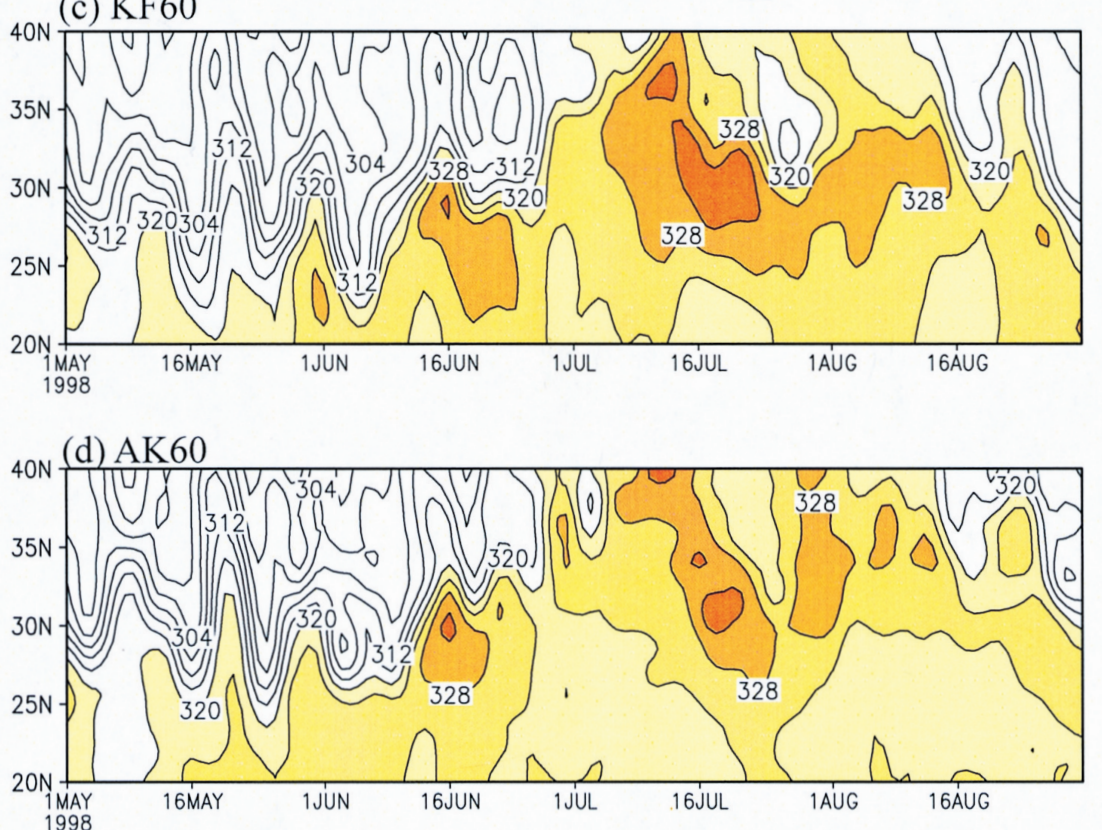

Fig. 6. The same as in Fig. 4 but for $850 \mathrm{hPa}$ equivalent temperature with contour intervals of $4 \mathrm{~K}$. 
The abnormal East Asia monsoon activity during the summer of 1998 is also shown in the time-latitude cross section of $850 \mathrm{hPa}$ equivalent temperature (Fig. 6). Similarly to observed precipitation, temporal and spatial variation of the East Asia monsoon front also appeared well in simulated $850 \mathrm{hPa}$ equivalent temperature field. The AK and GR schemes simulated the onset of the East Asia monsoon properly in mid-May. All schemes captured the transition of the monsoon front which shifted from southern China to central and northern China between early June and early July. However, in all runs, the equivalent temperature over southern China was underestimated in comparison with observation. Also, in the GR and KF schemes, the temporal pattern of simulated equivalent temperature during the second Mei-yu period from late July to the end of August was closer to observation in comparison with the AK scheme.

\subsection{Results of $20 \mathrm{~km}$ Horizontal Resolution}

As horizontal resolution increased from 60 to $20 \mathrm{~km}$, all schemes increased the amount of precipitation in the nested domain. In particular, heavy precipitation over southern China which was not captured in the $60 \mathrm{~km}$ resolution runs appeared with a small amount of precipitation in the $20 \mathrm{~km}$ resolution runs. However, in general, not much difference between the $60 \mathrm{~km}$ and $20 \mathrm{~km}$ resolution runs resulted in terms of the spatial patterns of precipitation.

Bias of the seasonal mean precipitation averaged over the land in the nested domain is shown in Table 2. In all $20 \mathrm{~km}$ resolution runs, precipitation increased but precipitation bias decreased compared to the $60 \mathrm{~km}$ resolution runs, since the region of analysis might include most of the intense precipitation. The increase of total precipitation in the $20 \mathrm{~km}$ resolution runs was due to the increase in convective precipitation with higher horizontal resolution, while non-convective precipitation in the $20 \mathrm{~km}$ resolution runs decreased in the GR scheme and the AK scheme, and was unchanged in the KF scheme compared to that in the $60 \mathrm{~km}$ resolution runs. In general, not only the EMS but also the CPS is sensitive to horizontal

Table 2. Simulated seasonal mean precipitation during the summer of 1998 (JJA) averaged over the land in the nested domain and its bias from observation $\left(7.5 \mathrm{~mm} \mathrm{day}^{-1}\right)$.

\begin{tabular}{ccccc}
\hline & & \multicolumn{2}{c}{ Simulation } & \multirow{2}{*}{ Bias } \\
Experiments & Total & Convective & Non-convective & \\
\hline GR60 & 6.8 & 1.9 & 4.9 & -0.7 \\
KF60 & 5.3 & 2.6 & 2.7 & -2.1 \\
AK60 & 6.0 & 5.4 & 0.6 & -1.5 \\
\hline GR20 & 7.3 & 2.8 & 4.5 & -0.1 \\
KF20 & 6.1 & 3.4 & 2.7 & -1.4 \\
AK20 & 7.1 & 6.8 & 0.3 & -0.4 \\
\hline
\end{tabular}


resolution. In Table 2, the change in convective precipitation was more sensitive to the increase of horizontal resolution from $60 \mathrm{~km}$ to $20 \mathrm{~km}$ than that in non-convective precipitation. One of the possible reasons for more sensitivity of the CPS to horizontal resolution can be understood in terms of the calls of physical process in the integration of the model. Since the call of CPS precedes the call of EMS in the model, the CPS can be affected by the increase of horizontal resolution earlier than the EMS. As horizontal resolution increased, all three schemes were likely to increase convective precipitation. The increase in convective precipitation in AK20 implied the increase of moisture convergence by the increase in horizontal resolution as demonstrated in the study of Wang and Seaman (1997). In GR20 and KF20, the increase in convective precipitation resulted from the change in vertical mass flux, since the precipitation efficiency was not much changed by the increase of horizontal resolution. This increase in convective precipitation in all $20 \mathrm{~km}$ runs could decrease the activity of the EMS, because the CPS reduced the amount of water vapor which could be resolved by the EMS, and the atmospheric condition was stabilized due to the increasing convective process. Consequently, the increase in horizontal resolution led to increased convective precipitation, and decreased or unchanged non-convective precipitation.

Figure 7 shows the percentage distribution of daily precipitation intensity during the summer of 1998 (JJA) averaged over the land in the nested domain for all experiments. The frequency of occurrence of daily precipitation events within the given intervals of intensity was divided by the total number of daily precipitation events. The maximum frequency of observed precipitation $\left(5-10 \mathrm{~mm} \mathrm{day}^{-1}\right)$ was well captured in all runs. However, in the $60 \mathrm{~km}$ resolution runs, frequencies of weak precipitation intensity below $5 \mathrm{~mm}^{\text {day }}{ }^{-1}$ were much higher than observation, and those in the $20 \mathrm{~km}$ resolution runs were much reduced compared to those in the $60 \mathrm{~km}$ resolutions runs. In the $60 \mathrm{~km}$ runs, the GR scheme simulated a relatively lower frequency of weak precipitation but a relatively higher frequency of the maximum peak than other schemes, while the KF and the AK schemes were opposite to the GR scheme below $5 \mathrm{~mm} \mathrm{day}^{-1}$. It is noted that the intensity at $5-10 \mathrm{~mm} \mathrm{day}^{-1}$ much increased in the $20 \mathrm{~km}$ resolution runs in comparison to that in the $60 \mathrm{~km}$ resolution runs. This slight enhancement of summer precipitation intensity with the increase of horizontal resolution was related to the increase in local convective rain. Above an intensity of $10 \mathrm{~mm}_{\text {day }}{ }^{-1}$, none of the CPSs simulated reasonable precipitation intensity, in particular, the KF scheme.

\section{VERTICAL STRUCTURE AND ENERGY BUDGET}

Since the vertical distribution of atmospheric variables can be different amongst CPSs, we analyzed the vertical profiles of wind, water vapor mixing ratio, temperature, and relative humidity biases (Fig. 8). The biases were calculated from seasonal mean values of model outputs and NCEP reanalysis 2 data averaged over the land in the nested domain. There were not large differences in the vertical distribution of variables between horizontal resolutions, so only the results from $60 \mathrm{~km}$ resolution runs are discussed.

In all the $60 \mathrm{~km}$ horizontal resolution experiments, the low-level zonal wind was overestimated and the upper-level zonal wind was underestimated (see Fig. 3), and both the low- 


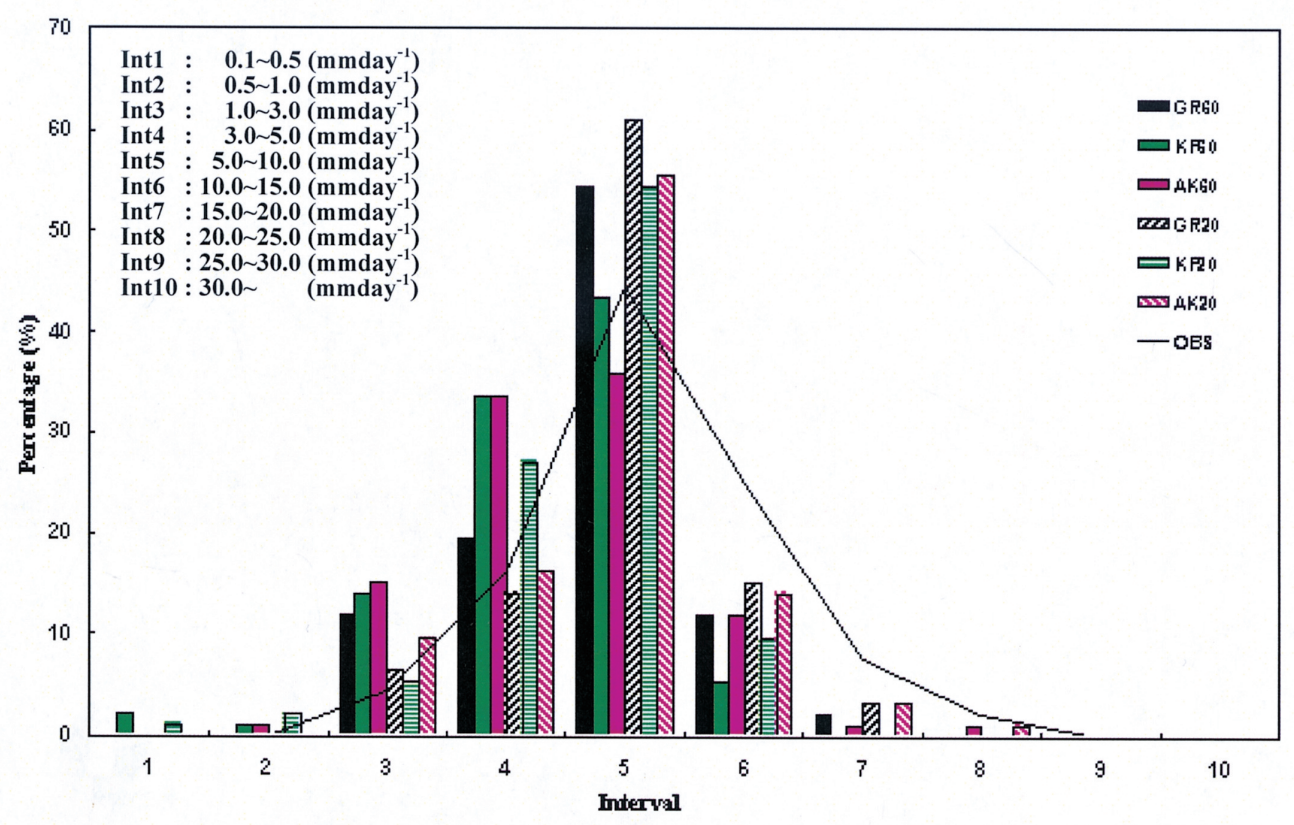

Fig. 7. Daily precipitation intensity averaged over the land in the nested domain during the summer of 1998 (JJA) in observation and simulations. The frequency of intensity within a given interval is represented as the percentage of the total number of rain events.

level and the upper-level meridional wind were overestimated. The low-level wind was much more sensitive to CPS than the upper-level wind. As mentioned in the previous section, the low- and mid-level wind in the AK runs was much overestimated due to the increasing temperature gradient between the land and the ocean in comparison to other scheme runs. In general, the GR scheme and the KF scheme which are CPSs of a mass flux type tend to simulate a similar vertical structure of horizontal wind to each other.

In the vertical profile of air temperature, the GR and KF schemes simulated a warm bias in the upper layer and a cold bias in the lower layer, although the AK scheme simulated cold bias below $350 \mathrm{hPa}$ and warm bias above it. The GR and KF schemes simulated the maximum bias at about $300 \mathrm{hPa}$ and the minimum bias at about $900 \mathrm{hPa}$ but the AK scheme simulated both the maximum and the minimum bias about $100 \mathrm{hPa}$ higher than those in the GR and KF schemes. Similarly to the wind field, the vertical profiles of air temperature in the AK run were also quite distinct from those in the GR and KF runs. The low-level air temperature in the GR and KF runs was much underestimated due to the cooling effect by a downstream process compared with in the AK run. It is noteworthy that in spite of more convective rain, the midlevel air temperature in the AK run was cooler than those in the other runs. One of the reasons for the different vertical structure between the AK run and the other runs is likely that the AK scheme uses an assumed heating profile which distributes atmospheric latent heat to the envi- 
(a) Zonal wind in $60 \mathrm{~km}$ simulations $\left(\mathrm{m} \mathrm{s}^{-1}\right)$

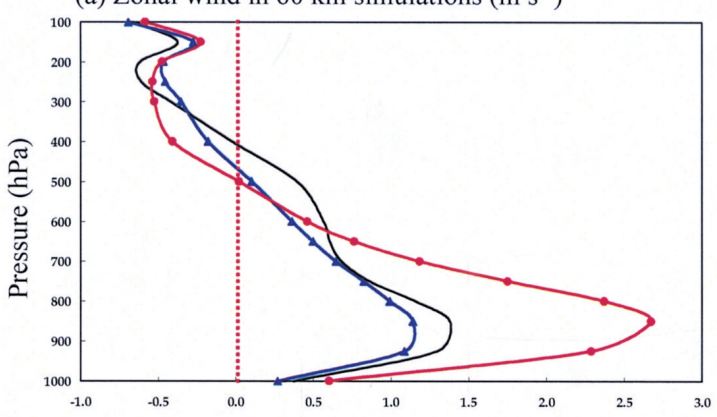

(c) Air temperature in $60 \mathrm{~km}$ simulations $\left({ }^{\circ} \mathrm{C}\right)$

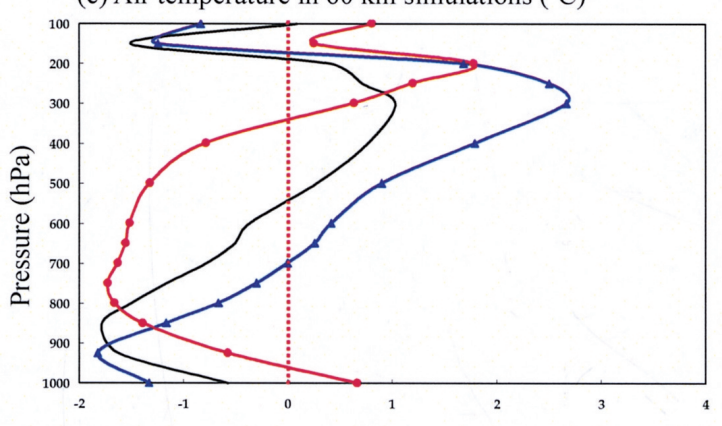

(b) Meridional wind in $60 \mathrm{~km}$ simulations $\left(\mathrm{m} \mathrm{s}^{-1}\right)$

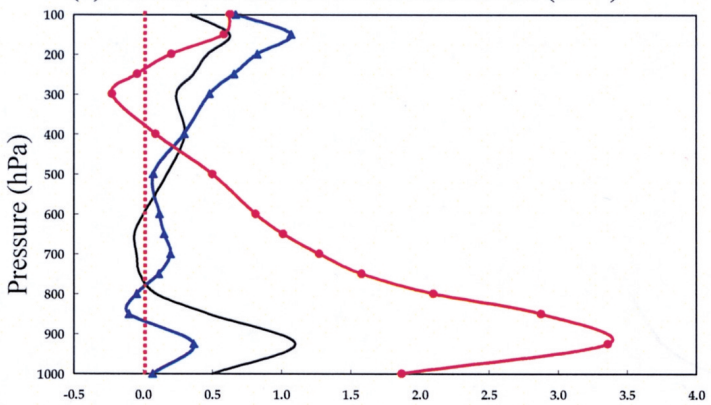

(d) Water vapor mixing ratio in $60 \mathrm{~km}$ simulations $\left(\mathrm{g} \mathrm{kg}^{-1}\right)$

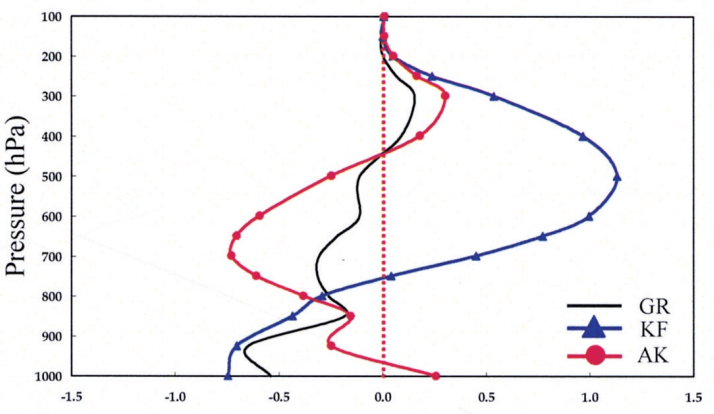

Fig. 8. Vertical profiles of seasonal mean bias (model - reanalysis) in (a) zonal wind and (b) meridional wind, (c) air temperature, and (d) water vapor mixing ratio during the summer of 1998 (JJA) averaged over the land in the nested domain.

ronmental atmosphere through condensation of water vapor.

In KF60, the water vapor between $750 \mathrm{hPa}$ and $200 \mathrm{hPa}$ was likely overestimated in comparison to the reanalysis, because the water vapor was not condensed by the EMS due to the enhanced convective process. On the other hand, in AK60, the water vapor tended to be underestimated in the mid-layer between $800 \mathrm{hPa}$ and $500 \mathrm{hPa}$, since water vapor flux was released according to a parabolic reference profile, and more water vapor near the surface was simulated in comparison to GR60 and KF60. In GR60, less water vapor at the low-level below $800 \mathrm{hPa}$ was simulated in comparison with the reanalysis, but the bias of water vapor was smallest at the mid- and upper-level over $800 \mathrm{hPa}$. Less water vapor at the low-level in GR60 and KF60 in comparison to AK60 might be caused by the cooling effect of a downstream process and less latent heat flux at the surface.

We also analyzed the vertical profiles of seasonal mean (JJA) atmospheric hydrometeors such as rain water and cloud water averaged over the land in the nested domain (Fig. 9). In the 
(a) Rain water in $60 \mathrm{~km}$ simulations $\left(10^{-5} \mathrm{~kg} \mathrm{~kg}^{-1}\right)$

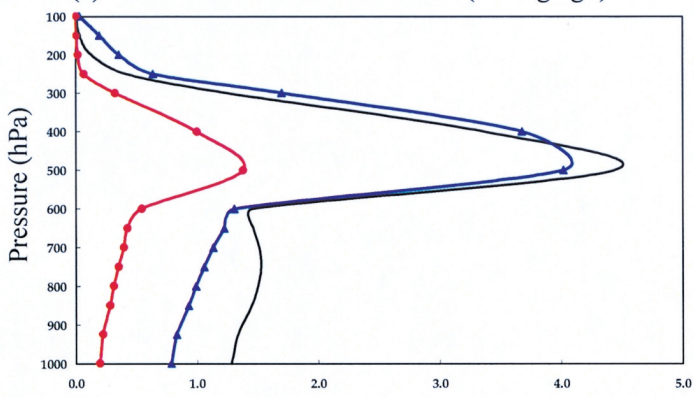

(c) Cloud water in $60 \mathrm{~km}$ simulations $\left(10^{-5} \mathrm{~kg} \mathrm{~kg}^{-1}\right)$

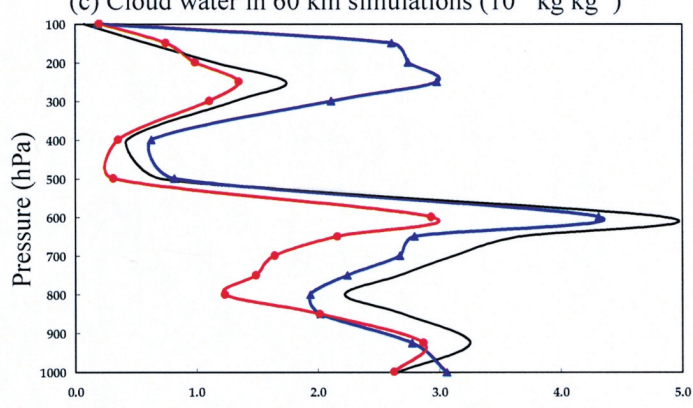

(b) Rain water in $20 \mathrm{~km}$ simulations $\left(10^{-5} \mathrm{~kg} \mathrm{~kg}^{-1}\right)$

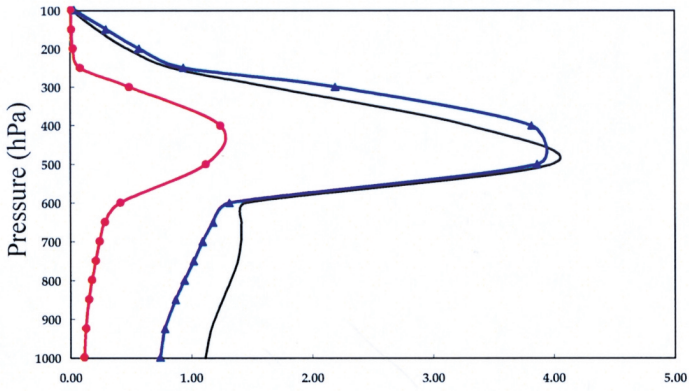

(d) Cloud water in $20 \mathrm{~km}$ simulations $\left(10^{-5} \mathrm{~kg} \mathrm{~kg}^{-1}\right)$

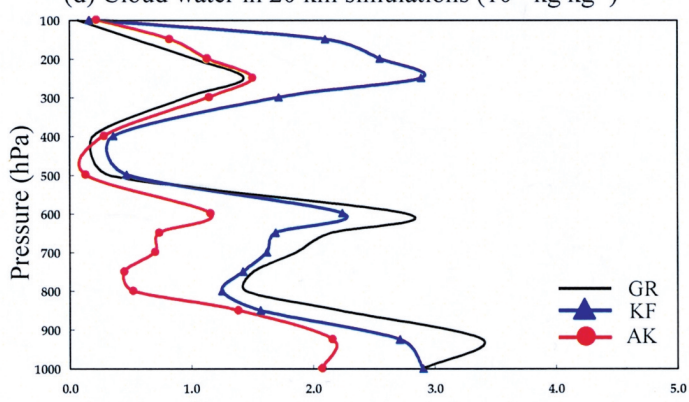

Fig. 9. Vertical profiles of seasonal mean $(\mathrm{a}, \mathrm{b})$ rain water, and $(\mathrm{c}, \mathrm{d})$ cloud water during the summer of 1998 (JJA) averaged over land in the nested domain.

vertical profile of rain water, the GR and the KF scheme which had similar patterns to each other simulated most of the rain water between 300 and $600 \mathrm{hPa}$, while the AK scheme simulated a very small amount of rain water in comparison with the GR and KF schemes. Rain water also decreased very slightly at the low level in all schemes as horizontal resolution increased. In all schemes, the pattern of cloud water vertical distribution was simulated with a maximum at $600 \mathrm{hPa}$ and a minimum between 400 and $500 \mathrm{hPa}$. In the vertical profile of cloud water, there was a significant difference between 60 and $20 \mathrm{~km}$ resolution experiments below about $500 \mathrm{hPa}$, but not much difference above $500 \mathrm{hPa}$. As horizontal resolution increased from 60 to $20 \mathrm{~km}$, the cloud water decreased by $40-60 \%$ in all schemes. In general, the difference in vertical profile between the CPSs was significant, but that between horizontal resolutions was small except for the case of cloud water. As horizontal resolution increased, increasing precipitation resulted from the decreasing cloud water mainly below $500 \mathrm{hPa}$.

We analyzed the seasonal mean (JJA) surface energy budget averaged over the land in the nested domain in order to investigate the sensitivities of surface energy fluxes to CPS and horizontal resolution (Table 3). In both the 20 and $60 \mathrm{~km}$ horizontal resolution experiments, the variations of the downward solar radiation and latent heat flux at the surface were significantly large. In the KF scheme, less incoming solar radiation and latent heat flux at the surface resulted, while the AK scheme simulated more incoming solar radiation and latent heat flux at 
Table 3. Surface energy budgets during the summer of 1998 (JJA) averaged over the land in the nested domain in all simulations. $S_{\text {down }}, L_{\text {down }}, S_{\text {up }}$, $\mathrm{L}_{\mathrm{up}}, \mathrm{S}_{\mathrm{h}}, \mathrm{L}_{\mathrm{h}}$, and $\mathrm{G}$ indicate incoming solar radiation, incoming longwave radiation, outgoing solar radiation, outgoing longwave radiation, sensible heat flux, latent heat flux, and heat flux into soil at the surface, respectively. Units are $\mathrm{Wm}^{-2}$.

\begin{tabular}{rrrrrrrr}
\hline Experiments & $\mathrm{S}_{\text {down }}$ & $\mathrm{L}_{\text {down }}$ & $\mathrm{S}_{\text {up }}$ & $\mathrm{L}_{\text {up }}$ & $\mathrm{S}_{\mathrm{h}}$ & $\mathrm{L}_{\mathrm{h}}$ & $\mathrm{G}$ \\
\hline GR60 & 199.4 & 406.0 & 33.7 & 449.0 & 20.7 & 97.2 & 5.1 \\
KF60 & 167.1 & 404.2 & 28.8 & 443.8 & 14.1 & 80.2 & 4.6 \\
AK60 & 219.5 & 408.0 & 37.2 & 456.1 & 20.6 & 108.1 & 5.5 \\
\hline GR20 & 216.1 & 402.8 & 36.5 & 447.1 & 22.4 & 107.6 & 4.9 \\
KF20 & 193.1 & 402.5 & 32.9 & 444.9 & 17.3 & 96.2 & 4.7 \\
AK20 & 237.2 & 401.9 & 40.2 & 453.6 & 19.9 & 119.4 & 5.3 \\
\hline
\end{tabular}

the surface than other schemes. These differences of incoming solar radiation and latent heat between the CPSs could be attributed to the differences of vertical distribution of atmospheric hydrometeors. In the model, atmospheric hydrometeors are separated into atmospheric water vapor, cloud water, and rain water. In the vertical profiles of atmospheric hydrometeors, the AK scheme produced less atmospheric hydrometeors compared with the GR and KF schemes (see Fig. 9). Conversely, the KF scheme produced much more water vapor, cloud water and rain water than the AK scheme, and more water vapor than the GR scheme. Therefore, in the $\mathrm{KF}(\mathrm{AK})$ runs, the incoming solar radiation at the surface decreased (increased) relatively since atmospheric hydrometeors absorbed more (less) downward solar radiation in the atmosphere. Differences of incoming solar radiation at the surface between the CPSs could induce different surface latent and sensible heat fluxes. For example, more incoming solar radiation in the AK run resulted in more latent and sensible heat release at the surface compared with other runs. Also, in all schemes, the incoming solar radiation and latent heat at the surface increased with increasing horizontal resolution. The reason for this is because atmospheric hydrometeors, in particular, cloud water decreased with increasing horizontal resolution, so that the incoming solar radiation at the surface increased. It is also noteworthy that differences in the long-wave radiation and sensible heat flux at the surface between all 60 and $20 \mathrm{~km}$ runs were relatively less than those of solar radiation and latent heat flux.

\section{DIURNAL VARIATION}

To examine the impact of the CPSs and the horizontal resolution on diurnal variation in the regional climate simulation, we analyzed the diurnal variation of precipitation during the summer of 1998 (JJA) in the nested domain. Figure 10 shows diurnal variation of the 3-hour 
(a) Total rain in $60 \mathrm{~km}$ simulations $(\mathrm{mm})$

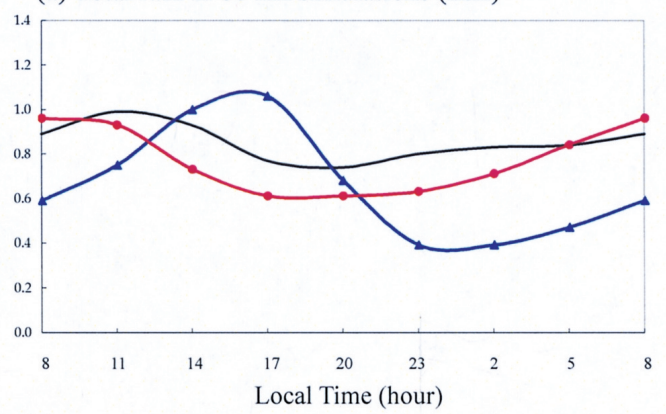

(c) Convective rain in $60 \mathrm{~km}$ simulations $(\mathrm{mm})$

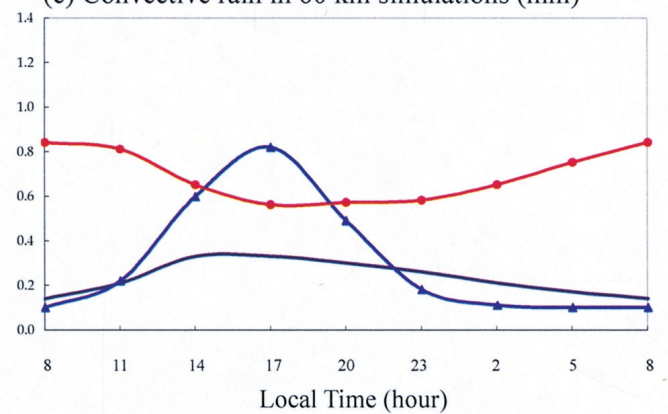

(e) Non-convective rain in $60 \mathrm{~km}$ simulations (mm)

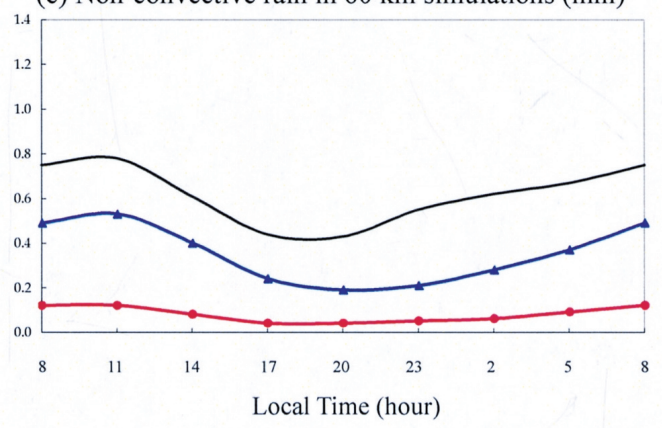

(b) Total rain in $20 \mathrm{~km}$ simulations $(\mathrm{mm})$

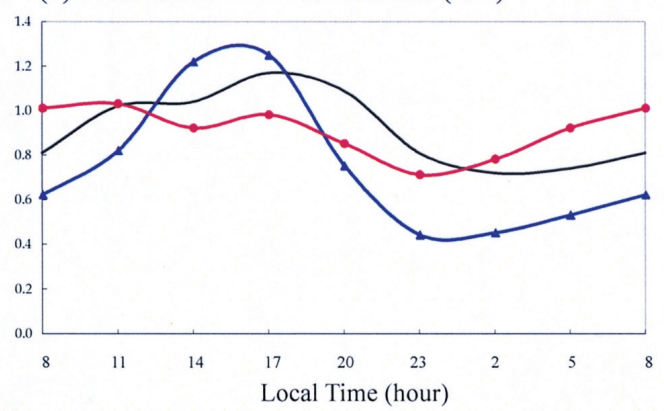

(d) Convective rain in $20 \mathrm{~km}$ simulations ( $\mathrm{mm})$

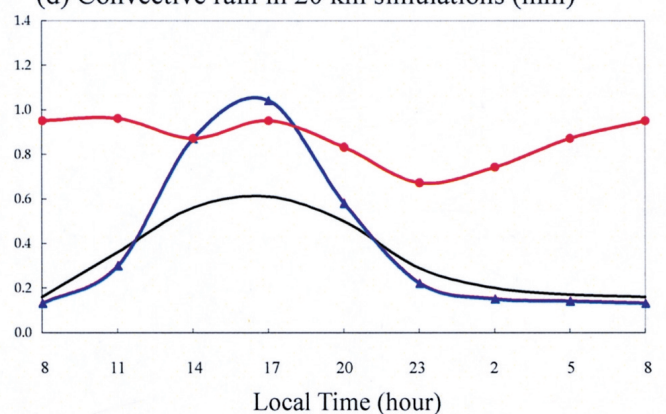

(f) Non-convective in $20 \mathrm{~km}$ simulations (mm)

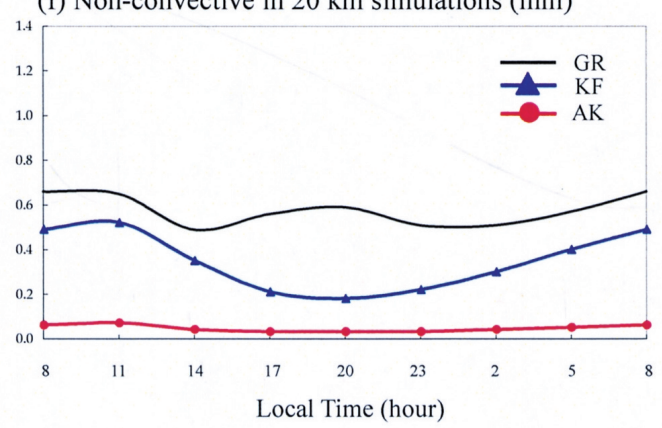

Fig. 10. Diurnal variations of simulated 3-hour (a, b) total rain (mm), (c, d) convective rain and $(\mathrm{e}, \mathrm{f})$ non-convective rain $(\mathrm{mm})$ averaged over land in the nested domain.

accumulated precipitation averaged over land in the nested domain, during the summer of 1998 (JJA). In GR60, the maximum peak of total precipitation appeared at about 11 am local time and the total precipitation decreased until evening, then increased from nighttime to morning. The diurnal variation of total precipitation in GR60 was similar to that of non-convective precipitation rather than convective precipitation. Since the total precipitation in GR60 was dominated by non-convective rain during the whole day, the portion of convective rain to 
total rain was small. This is the reason why non-convective precipitation tended to occur in the night and early morning when relative humidity was high during the day. Therefore, in GR60, more of the total precipitation was simulated in the nighttime and morning than in the afternoon. In AK60, the maximum peak of total precipitation appeared at about 8 am and the total precipitation decreased in the daytime and increased in the nighttime. The total precipitation in AK60 was strongly dominated by convective rain, so that the diurnal variation of total precipitation corresponded to that of convective rain. In AK60, more convective precipitation in the night and the morning was likely to be related to the diurnal variation of moisture convergence and relative humidity at the low level which could trigger atmospheric convection in the AK scheme. Diurnal variation of total precipitation in KF60 was different from those in GR60 and AK60. In KF60, more convective rain resulted than non-convective rain in the daytime, so that the total precipitation was dominated by convective rain in the daytime but dominated by non-convective rain in the nighttime. Therefore, the maximum peak of total rain appeared at about $5 \mathrm{pm}$. The increase of convective rain in the daytime in KF60 can be related to the basis of the Kain-Fritch scheme that convection is triggered by CAPE which increases in the daytime.

The diurnal variations of total precipitation in the $20 \mathrm{~km}$ horizontal resolution runs were different from those in the $60 \mathrm{~km}$ horizontal resolution runs. In GR20, the maximum peak time of total precipitation was shifted from forenoon to early evening, because convective rain in GR20 increased, in particular in the daytime, compared with GR60. Non-convective rain also increased in the evening in GR20. In AK20, the diurnal variation of total precipitation had double maximum peaks, the first appearing between 8 am and 11 am and the second at about $5 \mathrm{pm}$. This is the reason why convective rain in AK20 increased prominently in the afternoon between $2 \mathrm{pm}$ and $5 \mathrm{pm}$ unlike with AK60. In KF20, the diurnal variation of total precipitation was similar to that in KF60, because only convective rain during the daytime increased slightly with the $20 \mathrm{~km}$ horizontal resolution. It is noted that the maximum peaks in the $60 \mathrm{~km}$ resolution experiments appeared at different times between CPSs, but all the maximum peaks in the $20 \mathrm{~km}$ resolution experiments appeared in the early evening around $5 \mathrm{pm}$ The reason for this is that in the $20 \mathrm{~km}$ resolution experiments, the maximum peaks in the early evening are attributable to increasing latent heat flux at the surface during the daytime.

\section{DISCUSSIONS AND SUMMARY}

In this study, we performed regional climate simulations using a regional climate model, SNURCM, with the $60 \mathrm{~km}$ horizontal resolution in order to investigate the sensitivity of the regional climate simulation over East Asia to three CPSs. We also conducted nesting experiments with the $20 \mathrm{~km}$ horizontal resolution, since most CPSs are sensitive to horizontal resolution.

Markedly different characteristics of precipitation were simulated as a result of the difference in the CPSs, although extreme floods over East Asia during the summer of 1998 were captured by all $60 \mathrm{~km}$ runs. In the GR run, about $70 \%$ of the total precipitation was simulated as non-convective precipitation, so that heavy precipitation over East Asia, which was af- 
fected by anomalous large-scale conditions, was reasonably simulated. However, the KF scheme simulated less non-convective precipitation than the GR scheme due to the enhanced convective process in the KF run, so that the total precipitation in the KF run was relatively underestimated. Also, the statistics of seasonal mean precipitation in the AK run were better than those in other runs, because convective precipitation in the AK runs is determined by large-scale synoptic fields such as vertically integrated moisture convergence and atmospheric relative humidity.

In low- and upper-level wind field, spatial distributions between CPSs were similar to each other due to the implementation of a spectral nudging technique but the strength of the wind, especially low-level wind, varied greatly between CPSs. This variation in low-level wind resulted from the difference in pressure gradient between the land and the ocean, which depends upon the sensitivity of surface air temperature to the CPS. The temporal evolution of the East Asia monsoon was also simulated as being sensitive to the CPS. In terms of the timelatitude cross section of the precipitation and the equivalent temperature over the East Asia monsoon region, the East Asia monsoon activities were properly simulated in all runs. However, AK and GR schemes captured well the temporal and spatial variation of the monsoon from the onset to the development period, and the GR and KF schemes simulated it reasonably from late July to the end of August.

With a higher horizontal resolution of $20 \mathrm{~km}$, all schemes tended to increase the total precipitation due to the increase of convective precipitation in the nested domain, so that the simulation of heavy precipitation over southern China during the summer of 1998 was improved. However, little difference resulted between the 60 and $20 \mathrm{~km}$ resolution runs in terms of the spatial patterns of precipitation. Precipitation intensity was to some extent sensitive to the CPS, although all the schemes captured the observed maximum peak of precipitation. The precipitation intensity was also slightly enhanced due to the increase in convective precipitation with the higher horizontal resolution.

The vertical profiles of wind, air temperature, water vapor, and atmospheric hydrometeors were more sensitive to the CPS than to horizontal resolution. The vertical structures in the GR and KF run were similar to each other, and different from those in the AK run. The sensitivity of vertical structure of cloud water to horizontal resolution was relatively large. The different vertical structure of atmospheric hydrometeors between the CPSs resulted in the difference in surface energy fluxes. Since the amounts of cloud in all schemes tended to decrease with higher horizontal resolution, the incoming solar radiation and latent heat flux at the surface increased. Also, convective precipitation can increase due to enhanced surface latent heat flux, because the change in surface latent heat flux can modify the triggering of convective activities.

Diurnal variation of precipitation was also sensitive both to CPS and to horizontal resolution. The maximum peak of total precipitation occurred in the mornings of GR60 and AK60, while the maximum peak of total precipitation appeared in the afternoon in KF60. As a higher horizontal resolution was used, the maximum peak of total precipitation in GR20 and AK20 appeared at about $5 \mathrm{pm}$ unlike with the $60 \mathrm{~km}$ runs because of the increase in latent heat flux in the daytime.

This study showed that RCM simulated substantially different regional climates during 
the 1998 East Asian summer monsoon when different CPSs were used, and that the AK and GR schemes simulated more reasonably the 1998 summer flood over East Asia which was affected by anomalous large-scale conditions rather than the KF scheme. The AK scheme reproduced the East Asian Summer precipitation on the whole, despite its flaws in thermodynamic processes that Raymond and Emanuel (1993) also pointed out. The reasonable simulation of the precipitation in the AK run can be attributed to its intrinsic triggering assumptions which might be proper to the characteristics of the East Asian summer precipitation, and the reasonable simulation of large-scale monsoon circulations due to the spectral nudging technique. Despite worse precipitation statistics of the GR scheme than the AK scheme, the GR scheme simulated reasonably atmospheric vertical structure and temporal evolution of the East Asian Summer monsoon due to its proper atmospheric thermodynamic processes. Also, the GR scheme simulated relatively better precipitation due to non-convective precipitation portion in comparison with the KF scheme. Therefore, the GR scheme was on the whole suitable to simulate the East Asian summer heavy precipitation, consistent with the study of Yang and Tung (2003). The KF scheme which is the most sophisticated scheme amongst the three schemes had the worst statistics in the precipitation simulation due to a relatively small portion of non-convective precipitation, although it simulated more convective precipitation in the $20 \mathrm{~km} \mathrm{run}$. To improve the precipitation simulation using the KF scheme over East Asia, it would be necessary to conduct additional sensitivity tests to the physical processes, lateral boundary condition, and horizontal and vertical resolution in the SNURCM. Also, the proper tuning of the parameters in the KF scheme for East Asian summer precipitation would be needed in the SNURCM.

Further studies for more cases are also necessary to find better CPS's role for general regional climate simulation over East Asia since the results of this study are based on only one case with very intense summer precipitation. Also, more sensitivity experiments considering other physical processes (e.g., explicit moisture, radiation, PBL processes) are suggested for a general conclusion to be reached. Nonetheless, we think that this study can provide a useful reference for long-term regional climate simulations over East Asia.

Acknowledgements This study was supported by the BK21 program of the Korean Government Ministry of Education, and the project of Prediction and Impact Assessment of Water Cycle with Climate Change in the Eco-technopia 21 project funded by the Korean Government Ministry of Environment. The authors would like to acknowledge the support from KISTI (Korea Institute of Science and Technology Information) under "The Sixth Strategic Supercomputing Support Program". The use of the computing system of the Supercomputing Center is also greatly appreciated. The authors also express their appreciation to Drs. Hans von Storch and Frauke Feser at the GKSS Research Centre for providing the source code for spectral nudging and to the National Center for Atmospheric Research for access to surface observation data. 


\section{REFERENCES}

Anthes, R. A., 1977: A cumulus parameterization scheme utilizing a one-dimensional cloud model. Mon. Wea. Rev., 105, 270-286.

Arakawa, A., and W. H. Schubert, 1974: Interaction of a cumulus cloud ensemble with the large-scale environment. Part I. J. Atmos. Sci., 31, 674-701.

Bonan, G. B., 1996: A land surface model (LSM version 1.0) for ecological, hydrological, and atmospheric studies. Technical description and User's guide. NCAR Tech. Note, NCAR/TN-417+STR, 150 pp.

Briegleb, B. P., 1992: Delta-Eddington approximation for solar radiation in the NCAR community climate model. J. Geophys. Res., 97, 7603-7612.

Dickinson, R. E., R. M. Errico, F. Giorgi, and G. T. Bates, 1989 : A regional climate model for the western United States. Climatic Change, 15, 383-42.

Ding Y., and Liu Y., 2001 : Onset and the evolution of the Summer Monsoon over the South China Sea during SCSMEX Field Experiment in 1998. J. Meteor. Soc. Japan, 79, 255276.

Dudhia, J., 1989: Numerical Study of Convection Observed during the Winter Monsoon Experiment Using a Mesoscale Two-Dimensional Model. J. Atmos. Sci., 46, 3077-3107.

Fritsch, J. M., and C. F. Chappell, 1980: Numerical prediction of convectively driven mesoscale pressure systems, Convective parameterization.J. Atmos. Sci., 37, 1722-1733.

Giorgi, F., 1990: Simulation of regional climate using a limited area model nested in a general ciculation model. J. Climate, 2, 941-963.

Giorgi, F., and C. Shields, 1999: Tests of precipitation parameterizations available in the latest version of the NCAR regional climate model (RegCM) over the continental U.S. J. Geophys. Res., 104, 6353-6376.

Gochis, D. J., W. J. Shuttleworth, and Z. L. Yang, 2002: Sensitivity of the Modeled North American Monsoon Regional Climate to Convective Parameterization.Mon.Wea.Rev., 130, 1282-1298.

Grell, G. A., 1993: Prognostic evaluation of assumptions used by cumulus parameterizations. Mon. Wea. Rev., 121, 764-787.

Grell, G. A., J. Dudhia, and D. R. Stauffer, 1994: A description of the fifth-generation Penn State/NCAR mesoscale model (MM5). NCAR/TN-398+STR, NCAR Technical Note, NCAR, Boulder, CO. 122 pp. $\neq \neq \neq$

Hong, S. Y. and H. L. Pan, 1996: Nonlocal Boundary Layer Vertical Diffusion in a MediumRange Forecast Model. Mon. Wea. Rev., 124, 2322-2339.

Kain, J. S., and J. M. Fritsch, 1990: A one-dimensional entraining/detraining plume model and its application in convective parameterization. J. Atmos. Sci., 47, 2784-2802.

Kang, H. S., D. H. Cha, and D. K. Lee, 2004: Evaluation of the MM5/LSM Coupled Model for East Asian Summer Monsoon Simulations. J. Geophys. Res, 110, D10105, 1029/ 2004JD0005266.

Kida, H., T. Koide, H. Sasaki, and M. Chiba, 1991: A new approach to coupling a limited area model with a CGM for regional climate simulation.J. Meteor. Soc. of Japan, 69, 723-728. 
Kistler, R., and coathutors, 2001: The NCEP-NCAR 50-year reanalysis: Monthly means CDROM and documentation. Bull. Am. Meteor. Soc., 82, 247-268.

Kuo, H. L., 1974: Further studies of the parameterization of the influence of cumulus convection on large-scale flow. J. Atmos. Sci., 31, 1232-1240.

Lee, D. K., and M. S. Suh, 2000: Ten-year Asian summer monsoon simulation using a regional climate model (RegCM2). J. Geophys. Res., 105, 29565-29577.

Lee, D. K., D. H. Cha, and H. S. Kang, 2004: Regional climate simulation for the 1998 summer flood over East Asia. J. Meteor. Soc. Japan, 82, 1735-1753.

Leung, L. R., L. O. Mearns, F. Giorgi, and R. L. Wilby, 2003: Regional Climate Research. Bull. Am. Meteor. Soc., 84, 89-95.

Liang, X. Z., K. E., Kunkel, and A. N., Samel, 2001: Development of a Regional Climate Model for U.S. Midwest Applications. Part I: Sensitivity to Buffer Zone Treatment.J. Climate, 14, 4363-4378.

Liu, Y., R. Avissar, and F. Giorgi, 1996: Simulation with the RCMRegCM2 of extremely anomalous precipitation during the 1991 east Asian flood: An evaluation study. $J$. Geophys. Res., 101, 26199-26215.

Nuss, W. A. and D. W. Titley, 1994: Use of Multiquadric Interpolation for Meteorological Objective Analysis. Mon. Wea Rev., 122, 1611-1631.

Raymond D., and K. Emanuel, 1993: The Kuo cumulus parameterization. The Representation of Cumulus Convection in Numerical Models. Meteor. Monogr., 46, 145-150.

Smith, T. M., and R. W. Reynolds, 1998: A High-Resolution Global Sea Surface Temperature Climatology for the 1961-90 Base Period. J. Climate, 11, 3320-3323.

Von Storch, H., H. Langerberg, and F. Feser, 2000: A spectral nudging technique for dynamical downscaling purposes. Mon. Wea. Rev., 128, 3664-3673.

Wang, W., and N. L. Seaman, 1997: A comparison study of convective parameterization schemes in a mesoscale model. Mon. Wea. Rev., 125, 252-278.

Wang, Y., O. L. Sen, and B. Wang, 2003: A Highly Resolved Regional Climate Model (IPRCRegCM) and Its Simulation of the 1998 Severe Precipitation Event over China. Part I: Model Description and Verification of Simulation. J. Climate, 16, 1721-1738.

Xie, P., and P. A. Arkin, 1997: Global Precipitation: A 17-Year Monthly Analysis Based on Gauge Observations, Satellite Estimates, and Numerical Model Outputs. Bull. Amer. Meteor. Soc., 78, 2539-2558.

Xue, Y., H. M. H. Juang, W. P. Li, S. Prince, R. DeFries, Y. Jiao, and R. Vasic, 2004: Role of land surface processes in monsoon development: East Asia and West Africa.J. Geophys. Res., 109, D03105, doi:10.1029/2003JD003556.

Yang, M. J., and Q. C. Tung, 2003: Evaluation of rainfall forecasts over Taiwan by four cumulus parameterization schemes. J. Meteor. Soc. Japan, 81, 1163-1183.

Yin X., A. Gruber, and P. Arkin, 2004: Comparison of the GPCP and CMAP merged gaugesatellite monthly precipitation products for the period 1979-2001.J. Hydrometeor, 5, 1207-1222.

Zhang, G. J., and N. A. McFarlane, 1995: Sensitivity of climate simulations to the parameterization of cumulus convection in the Canadian Climate Centre general circulation model. Atmos. Ocean, 22, 407-446. 